\title{
The Low-Flying Communicator
}

\section{Understanding public relations in a regional context}

\author{
Jochen Hoffmann ${ }^{\mathrm{I}} \&$ James A. Lingwall ${ }^{\mathrm{II}}$ \\ 'Department of Culture and Learning, Aalborg University, Denmark \\ "Department of Communication, Clarion University of Pennsylvania, USA
}

\begin{abstract}
Most research on public relations (PR) roles takes the starting point of PR as an indispensable boundary-spanning function. Context may explain how PR is performed and which skills are important, but not the degree to which PR is necessary. In this article, we tackle the latter question by identifying and discussing the role of the low-flying communicator in the Danish region of North Jutland. The study is based on individual and focus group interviews with communication practitioners and students. The results show that many regional companies have established a communicative comfort zone "under the radar" of public attention. This leads to recruitment problems. Companies are less visible in the labour market and depend on graduates who stay in the region for personal reasons. A certain unwillingness to cross boundaries of social and public spaces feeds into sense-making but also contestable role understandings of PR practice and education in regional contexts.
\end{abstract}

Keywords: public relations education, public relations encroachment, public relations recruitment, public relations roles, regional public relations

\section{Introduction}

When searching for key concepts that describe what public relations (PR) is basically about, one quickly comes across the term boundary spanning: "Those who work with publics span boundaries - they interact with people outside their own group or organization" (Springston \& Leichty, 1994: 697). Boundary spanning must be understood in its social dimension; it is the ability to change the perspective and contribute to a corporate identity as a "looking-glass self" (Cooley, 1922/2007: 184). Boundary spanning enables an organisation to look at itself from the perspective of an external stakeholder, such as a critical activist group.

The respective boundaries have traditionally been between the organisation and the outside world, positioning PR primarily within the context of external stakeholder communication. Falkheimer and Heide (2014) take it a step further and look at internal processes as a context, where boundary spanning is also needed in order to respond to the polyphony of organisational communication (Trittin \& Schoeneborn,

Hoffmann, J., \& Lingwall, J. A. (2020). The low-flying communicator: Understanding public relations in a regional context. Nordicom Review, 41(1), 85-99. https://doi.org/10.2478/nor-2020-0007 
2017). Communication professionals could take a mediating role when, for example, comparing how legal and HR departments handle the same problems in different ways. Thus, Falkheimer and Heide (2014) go beyond a traditional understanding of public relations as external stakeholder management; they propose the broader term strategic communication, which ought to be developed into a "transboundary field of knowledge".

Boundary spanning as a role definition for professional communication is convincing on normative grounds, but that does not imply that it is the most convenient and effective way of doing PR in each and every context. This study examines PR as a sense-making practice embedded in a regional context: How much organisational boundary spanning is actually claimed and required here? Is there a modified or alternative role constituted by practitioners when accommodating with the regional context? And how do ambitions and expectations of communication students and alumni match or mismatch with a regional understanding of doing PR?

\section{$P R$ roles and $P R$ encroachment}

Much research on practitioner roles in the field of PR has been guided by the idea of strategic boundary spanning (Hoffmann et al., 2007; Leichty \& Springston, 1996), even though the term is not used much anymore. The concept of PR as "relationship management" (Ledingham \& Bruning, 1998) follows similar ideas. It turned into a more popular label and today describes a widely accepted understanding of strategic PR. In PR role research, the paradigm is reflected in Dozier and Broom's (1995) seminal manager-technician dichotomy. The respective functionalist perspectives on PR roles as strategic relationship management have been both differentiated and challenged over the years (for an overview, see Johansson \& Larsson, 2015). A range of context factors affecting PR practices have been taken into account. In sheer numbers, the most ambitious approach is the PR contingency theory that introduced 87 independent variables (Cameron et al., 2001). However, all of these context factors are confronted with one dependent variable alone. PR's boundary-spanning practices are measured on an advocacy-accommodation continuum aiming to identify to what degree PR influences or adapts to its stakeholders. The perceived need of PR as such is not a variable; neither did it contribute to PR role definitions that have been proposed over the years. Thus, both PR role concepts and newer developments such as the PR contingency theory have a "blind spot" in common, which triggered this study: looking at a distinct context that might question the relevance of PR per se.

It is within the context of cross-cultural PR research that a marginalisation of the PR function is observed and discussed. Functionalist scholars usually end up with a deficit diagnosis after measuring the degree of PR professionalism in "underdeveloped" countries against Western standards (for an overview, see Sriramesh \& Verčič, 2020). Respective research is guided by an ethnocentric mindset insisting on PR as an indispensable institution for "modern" societies (see the critique by Hoffmann, 2016). However, Aldrich and Herker (1977) argued more than 40 years ago that boundary-spanning positions in organisations are not necessarily prioritised by managers - once more, it depends on the context. They argue that boundary-spanning roles might be to some degree dispensable for well-established organisations within rather homogenous and stable environments - be it in the Global North or Global South (see also Meznar, 2005; 
Miles, 1987). Accordingly, there is also some empirical evidence from Europe that reveals a kind of paradoxical PR role whose key feature is a perceived lack of organisational importance. Röttger and colleagues (2003), for example, found that only a minority of the largest companies in Switzerland employ full-time professionals in a PR function - instead, broad job profiles dominate. PR is accomplished alongside other tasks and the job titles reveal no connection to communication at all. This falls in line with results from Denmark. Despite a considerable development and expansion of strategic communication during the twentieth century, PR continues to labour under an ambiguous status. Examining the Danish public sector, Kristensen (2010) found that communication professionals in Denmark often occupy a secondary position within their organisations.

Broad job profiles and the downplaying of the PR function are primarily critically discussed as a dysfunctional professional encroachment (Lauzen, 1992): employees without a specialised PR education and expertise take over PR functions. The potential subordination of PR to marketing through concepts such as integrated marketing communications are often perceived as a threat to the PR profession (Hutton, 2010). PR scholars express concerns about these tendencies, explaining them with internal structures and a top management that ignores the added value of PR (Lee, 2013). However, they hardly explain these tendencies through external context conditions. Reducing PR encroachment to an organisational pathology makes it impossible to incorporate it into a role definition that makes sense for organisational members when being confronted with a distinct organisational context.

We will argue that while PR encroachment might be critically discussed, it can still make sense in a regional setting. This may also affect role understandings of communication students in a regional higher education institution. We did not find any study identifying PR roles in regional contexts, and we only found one empirical study that systematically relates PR roles to PR education. Berkowitz and Hristodoulakis (1999) aimed to analyse differences between the role beliefs of practitioners and students. However, the predetermined decision to apply the traditional manager versus technician duality resulted in an idiosyncratic operationalisation (e.g., creativity as a technical skill) and an untransparent cluster analysis - including decisions such as: "Through heuristic methods, a two-cluster solution was chosen" (Berkowitz \& Hristodoulakis, 1999: 97). It is a type of study that reproduces the aforementioned blind spots in the research instead of discovering something new.

With this study, we aspire to discover something new. It starts from the stunning observation that there are hardly any empirical insights on PR in regional contexts. Moreover, research on PR roles has not yet responded to the increasing interest in dynamic processes of "vocational anticipatory socialization" (Myers et al., 2011). PR roles in different contexts are not only determined by senior professionals, but also by ambitions and expectations of communication students and graduates. This turns the regional microcosm of communication practice and education into a promising field of research.

When exploring such an unknown territory, it is important not to be guided by taken-for-granted assumptions that have been claimed or described in other contexts. Taking boundary spanning as an unquestioned benchmark would bear the risk that we automatically end up with a deficit diagnosis - similar to much functionalist international PR research measuring global communication practices against Western "standards". 
This study avoids such a pathologisation of potentially deviant role understandings. Instead, we aim to understand regional communication practices and student expectations as a microcosm in its own right. This, of course, does not mean forfeiting any critical perspective on the research subject. What makes sense for practitioners and students on the one hand, and is effective for organisations on the other, might still be challenged on normative grounds. Thus, we formulate two broad research questions which facilitate not only an explorative and unbiased - but also a critical - search for answers:

1. Which role understandings do communication practitioners constitute when relating their work to the regional context?

2. How do role understandings of communication students feed into or clash with regional practitioner roles?

\section{Method}

We completed our case study in the North Jutland region of Denmark. Its capital is Aalborg with approximately 114,000 inhabitants. The analysis is based on 1) qualitative interviews with communication heads of the largest companies in the region, 2) owners of communication agencies, and 3) alumni who graduated from Aalborg University. Furthermore, we conducted focus groups with 4) bachelor's students and 5) master's students from Aalborg University:

1. Companies Co1-Co7: We extracted from the global Orbis database the 25 biggest companies with headquarters in North Jutland. The annual financial turnover ranging from DKK 161 million to 2.6 billion - was used as an indicator for company size. We contacted the respective heads of communication by phone; seven agreed to an interview, five informed us that they do not have anybody in charge of communication, and thirteen rejected our interview request.

2. Agencies Ag1-Ag3: We used a variety of search terms on the classified Danish Yellow Pages in order to identify communication agencies in North Jutland that were at least partly engaged with public relations for private enterprises. We checked their websites, identified five suitable agencies, and contacted the owners; three agreed to an interview.

3. Alumni Al1-Al4: We identified seven alumni who (a) graduated between 2014 and 2016 from Aalborg University's International Business Communication (English stream) master's programme, (b) had a master's thesis stored in the library project database (which is not done in only a few cases where non-disclosure agreements cover the whole thesis), and (c) work now - according to online sources such as LinkedIn - in a communication-related position, which is (d) in a private enterprise and (e) located in North Jutland. Four of the seven alumni agreed to an interview.

4. Bachelor students Ba1-Ba4: We recruited first-semester students from the International Business Communication (English stream) bachelor's programme at Aalborg University. We conducted a short survey during a class and selected ten students from 42 responses who (a) are considering working for a company after graduation, (b) are considering a career in public relations, (c) do not yet have any practical 
experience in these fields, and (d) would be willing to participate in a focus group. We contacted these ten students, and four of them were able to join a focus group.

5. Master students Ma1-Ma3: We recruited ninth-semester students from the International Business Communication (English stream) master's programme at Aalborg University. From a total of twenty-seven students who did a mandatory internship in fall 2017, we chose seven students who did an internship that included PR-related tasks. Three of them were able and willing to join a focus group.

We chose focus groups with students over individual interviews in order to encourage peer discussions. It made the situation more comfortable for the students and avoided any potential association with an exam setting. The first focus group comprised one first-semester student and two ninth-semester students; the second focus group comprised three first-semester students and one ninth-semester student. We did qualitative face-to-face interviews with all other respondents. A pre-test was conducted with a communication professional from Aalborg University. The overall response was 43 per cent. We collected the data between mid-November 2017 and mid-February 2018. The average meeting length was 57 minutes. We guaranteed anonymity and the respondents agreed to the use of the data for scientific purposes.

All interviews and focus groups were conducted in English. When contacting the respondents, first by phone and also before we started with the interview on location, we asked them whether they felt comfortable doing the interview in English; they had no reservations. We had fluent conversations with them and they were able to express what they wanted to tell us. Naturally, they made occasional grammatical mistakes, but we stayed with a literal transcription of all communication. The following questions in particular related to the role of the regional context:

- How does the location in North Jutland affect the corporate communication of your company? What would be different, for example, if you were located in Copenhagen? (Asked of communication heads and alumni.)

- How does the location in North Jutland affect your recruitment activities when it comes to communication-related positions? (Asked of communication heads only.)

- How has the location affected your own career planning? Why did you decide to stay in North Jutland? (Asked of alumni only.)

- How does your current location here in North Jutland affect your career plans? What are the arguments to stay in the region, and what are the arguments to look for a job somewhere else? (Asked of students only.)

Overall, our data analysis followed basic principles of grounded theory (Glaser \& Strauss, 1967). First, we selected all excerpts relating somehow to the spatial dimension of the work or studies of the respondents - for example, the location in North Jutland - but have also included references to the global dimension of the business and the teaching programme. After some inductive reorganisation of categories, we ended up with four main themes contributing to role understandings by practitioners and students within the regional context: 1) Respondents described how they perceived the context and how or why they find it relevant for business communication. The second and third themes describe in detail how respondents claim and discuss two key characteristics 
which feed into regional PR roles: 2) the ambivalent broadness of communication practices and education, and 3 ) the prioritisation of a marketing orientation while at the same time downplaying public accountability. This led to the final theme which is 4) the discussion of recruitment challenges within the regional microcosm of communication practice and education.

\section{Findings}

The aggregation and interpretation of the four aforementioned themes which resulted from our grounded coding will answer our research questions: the identification of a practitioner and related student roles, which have not yet been found by previous research. We will argue that these roles are guiding sense-making practices that are particularly meaningful in a regional context. However, that does not necessarily mean that they are consistent, dominating, and uncontested. Accordingly, our analysis will also highlight ambivalences, tensions, and normative implications of regional PR roles.

\section{The relevance of the regional context}

What makes our sample unique is not the regional context alone, but a global orientation within a regional context. The participating students and alumni study or studied an internationally oriented programme. All of the communication heads from the companies, all of the alumni, and two of the three consultants deal to some degree with international stakeholders, even though this was not a selection criterion. While the global dimension of the workplace and the study programme is highlighted, the majority of the respondents tended to downplay the relevance of the location in North Jutland. For example, one said: "We are one big city in Denmark; it doesn't matter" (Co4) or: "The whole world is our workplace" (Co7). Similarly, Co2 argued that their company does not "have a special Jutland focus or anything. It's not really an issue for us", which means, as a consequence: "I don't communicate very much regionally" (Ag2). These quotes reveal a kind of nosense-of-place attitude. One student explained that "with the technology today you are able to work from [...] wherever" (Ba1). Respondents presented themselves and their institutions as professional "global players" and rather avoided associations with what might be perceived to be "provincial".

The downplaying of the region's relevance could be explained by a social desirability bias, because the very same respondents turned out to be quite sensitive towards some unique regional context factors that ultimately affected their role understandings. In the context of professional communication, respondents argued that personal networks matter more in North Jutland than on the national or global level (Ag2; Ag3; A12; A14). Work was described as a "people's business", allowing a "more friendly way of communicating" (Ag2), which would make it, for example, easier to pitch a story to a journalist (see also A12). Living and doing professional communication in North Jutland appears to be more easygoing than in a metropolitan area. One student argued: "I have been living in Copenhagen for half a year, and it was quite stressful, whereas Aalborg is really relaxed and very home-like and friendly and kind of small-townish" (Ba1). All three communication consultants stressed they do not have many competitors in the region. 
However, a relaxed business atmosphere is also perceived to be ambivalent; it can contribute to professional isolation, which is the opposite of boundary spanning. Al4 argued that less competition would result in fewer professional opportunities, and A12 praised Copenhagen's "whole other different flow and another energy [...] with the input they get from all over the place. We are more or less on our own here, on top of the hill".

The laid-back and potentially self-referential communication style can also be explained with a distinct cultural feature. CO3 referred to so-called "Janteloven", which describes a preference for social uniformity - people are not supposed to stand out from the rest or claim that they are somehow special. Janteloven affects PR; for example, Morsing and colleagues (2008) argue that Danish publics are rather reserved towards the explicit promotion of corporate social responsibility. Janteloven has been described as a feature of all Nordic countries (see, e.g., Bromgard et al., 2014, for Norway), though some respondents argued that it is even more salient in North Jutland:

- "Don't be the smart guy coming and saying, 'Oh, I'm so good and I can do the whole thing in half time'. That's not interesting, especially in the Northern part of Denmark" (Co3).

- “We won't brag of our products. [...] It's okay to say it's good, but we don't say anything is very good" (Co3).

- "Maybe it is because we are in the Northern part of Jutland, I don't know, but, whom you see is who we are. We are not trying to exaggerate who we are. You can say sometimes we should brag a bit more [...], but we are very conservative" (Co5).

- "We are a company which is very Nordjysk [North Jutland-like]. So we are not the high-flying guys. we are very low-flying and happy with that" (Co6).

The low-flying style of communication is not least influenced by the industry context. The respondents are primarily engaged with business-to-business (B2B) communication: "We are not Coca-Cola" (Co2) and "not Telenor or making new smart apps" (Co4). Applicants for communication positions should be aware of the B2B context:

If you are looking for something where you are going to be the big shot in marketing and communication [...], that's not our company. [...] You will probably never see the advertising, the TV commercials, the promotions we are doing, because they are going on in distribution channels where you rarely will be setting your foot $[\ldots]$, so you'll not be somebody who can say, well, I did this new Audi commercial. (Co6)

This confirms another argument of Aldrich and Herker (1977), who write that boundary spanning roles are negligible if the products and services themselves do not cross significant boundaries. That seems to be the case in the region's B2B sector.

The remote regional context, the reserved culture of Janteloven, and the niche character of B2B contexts is at odds with an understanding of public relations as a proactive selfpromotional boundary-spanning communication directed towards a diversity of publics. What we rather find in the region is the low-flying communicator who is fundamentally questioning an added value of public attention: "We don't feel the need to be very visible" (Co6). The following sections discuss the consequences of low-flying communication for job profiles, the relation to marketing, and regional recruitment. 


\section{The ambivalence of broadness}

We asked both the communication heads and the alumni to describe their current tasks. All of them are engaged in PR, but it is seldom the core of their profile. PR is mentioned along with other tasks such as human resources, business development, product development, accounting, sales, and not least marketing (Ag1; Ag2; Al2; Al4; Co1; Co2; Co3; Co4; Co5; Co6; Co7). It can be assumed that even some of the largest companies in the region do not have positions that include any PR tasks whatsoever. As mentioned above, 5 out of the 18 companies who rejected our interview request argued that they have nobody in charge of communication. Two of the three consultants we interviewed use that market opportunity and offer specialised services, such as media relations for regional players who lack the respective in-house resources.

Company representatives in turn do not see much need for specialised PR roles and large communication departments. Instead, "jack-of-all-trades" (Co6) would be the preferred job profile: "I have many titles on my cap, more or less involved in everything" (Co5). The lack of specialised profiles is not necessarily seen as a problem; rather, it makes the work more diverse, and therefore, attractive (A12; Co2; Co3; Co4; Co5). The regional academic communication programme mirrors this broadness, which is also appreciated by students and alumni:

I actually got a very positive feedback on the structure of this education here, because they say that when they hire people, they normally hire people for a specific thing. And I was the first intern in that department so that they had someone who had a variety of knowledge in all the specific areas, you know, capable of working in communication, but also slightly knowledge on management and in between, was actually very positive with them. (Ma1; see also A14)

However, another master's degree student explained that the broadness of the education also carries a downside when it comes to the definition and presentation of a professional expertise:

I didn't feel like I knew anything and that I could create any value for anyone. I wasn't ready to do anything, because I think, the education is extremely broad and it's a good thing, but it can also be a downfall, because we know a little bit about a lot, so I didn't really feel like I could talk a whole lot about something: Oh, I know so much about this, or like: I'm supposed to be the expert in this. (Ma2)

A14 argued that colleagues and superiors may question the added value of communication positions in the organisation. Such a risk would be even higher, because employees in communication positions, even at the entry level, may sometimes be rather isolated in the organisation. This would mean no functioning sounding board for management, no advice from senior communication professionals, and no discussions with peers from a similar educational background. Communication experts might find themselves in the role of a "lone warrior": "I wear a lot of different hats during the day, which is exciting but also challenging. And it's been challenging for me because I am the only communication person here" (A14). The respondent concluded:

I think there are a lot of opportunities for graduates in smaller companies like this. But it requires that they are extremely independent, that they can do everything 
from start to finish. Because that's the thing here. I think if I was hired at a larger company, then someone else would have composed the strategy, and they would be able to tell me: Ok, you have this strategy and you need to carry out this activity, this activity, and this activity. And I would do that. But the thing is here, I have to do both. And honestly, I think that's difficult because I don't have ten years of experience to rely on.

The above quote illustrates the downside of broad role understandings. On the one hand, it offers the chance to take responsibilities and engage in a role-making process from an early stage in the career; on the other hand, this can be experienced as a lack of guidance. Instead of enjoying more freedom at the workplace, graduates may miss the "how-to" bullet-point lists from line managers. This, in turn, is not necessarily what employers are willing to provide. Co1 would like to work with independent and confident candidates, and understands recruitment as a corporate investment in "fresh perspectives". What they would get instead would be "too cautious" graduates asking constantly for "guidance". Similarly, Co2 perceived a lack of maturity and goal-orientation among students: "You are really not focused on what you are going to do afterwards. What is it? What is a business? What kind of demands do they put to me? What kind of demands can I put to them?". The respondent concluded: "They actually stand at the end with an academic diploma and maybe don't really know what their aspirations are". We won't argue that this observation is also an appropriate description for the participants in our focus groups. They voluntarily followed our invitation, and this alone indicates their willingness to reflect in depth about their own studies and career plans. However, even some of their responses revealed a kind of drifting indecisiveness:

My problem, when I wanted to choose an education, was, I didn't have any idea what I wanted to do. [...] It was very broad, so I didn't really have to decide right away. [...] I knew that it could open doors, like marketing or internal communication, HR, or even something completely different. (Ma2)

The student concluded: "I think it's a good way to kind of open our eyes as to what we want and we can kind of go down the road that we want. But I think I've never found the road that I want to go down".

Overall, we argue that the low-flying stance towards professional communication in a regional context correlates with the need for broad job profiles where core PR activities are only one task alongside others. Such a broadness makes jobs more diverse and allows junior professionals to take on responsibilities in the early stages of their career. However, the lone jack-of-all-trades warrior lacks the safety net of a larger communication department - graduates serving in entry-level positions might miss guidance and advice. This becomes a problem particularly for indecisive students, who are attracted to a broad university programme because it allows postponing reflections about one's own skills and professional aspirations.

\section{The dominance of marketing-focused thinking}

Despite the reported broadness and diversity of communication-related tasks, our data indicate a prioritisation of marketing and a focus on customers as stakeholders (Ag2; $\mathrm{Co} 2$; $\mathrm{Co} 3$; Co6; Co7). Other tasks play a role, but these are embedded into an overall 
instrumental business logic. The regional context and the lack of communication departments, which prevent a division of labour between specialised expert roles, serve as an explanation here:

I would say like for very big companies where you have like whole communication teams that only focus on like internal communication or that only focus on media coverage or press releases or corporate news and all that kind of things, then I'm sure that the pure communication part is good. But when you work [...] with sales, that you have to develop sales, that you have to position your product and all that, then you need the nose for business, [...] so when you talk about possibilities of employing communication people in North Jutland, then $[\ldots]$ there are very few workplaces that really have whole communication departments that only focus on that. Most of the companies would be more like business-oriented, that would have to sell a product, that would have to make a marketing plan, that would have to make a market entry plan, and then you build the story around that. (Co7)

The prioritisation of marketing-focused thinking does not sufficiently account for the role of corporations in wider society. Accordingly, practice areas traditionally associated with PR were downplayed: 1) Media relations designed to increase public visibility would not provide much added value to the company, even though a potential public interest was acknowledged: "The media would, if we allowed them, they would probably be interested, because we are quite a big company in the area" (Co6). However, then an instrumental reasoning led to the decision not to respond to such an interest:

Play along, we want to do that, so you need to put resources into feeding the media. Somebody has to spend time. Our managing director probably would have to spend time on talking more with the media. And what is the outcome for us from that? So we spend time, we spend resources, so the money is gone. What did we get back? That's for us the question. And visibility for the visibility, stakeholder visibility is not something we're interested in. [...] We're a privately-owned company, family-owned company, so basically as long as the family is happy [...], what's the problem, what is it you want to achieve? (Co6)

2) Dealing with NGOs is not on the priority list, either. Co3 represents an industry that is regularly under attack by activists. However, when asked whether that affects the communication work, the respondent said it does not. Activists would never come to the village in North Jutland, where the headquarters and the factory are located: "It's too far away from the highway". 3) Community relations were also perceived to be less important. Once more, a no-sense-of-place attitude becomes salient:

I heard some complaints from [...] local politicians, who came to visit us, who said that we did nothing for the local community in terms of sponsoring football clubs or whatever. You know, all these local patriotic kinds of things that apparently you need to do. But I don't give a fuck, so we haven't been doing it for many years. [...] I have had a lot of meetings with them, but we cannot even find somewhere to put our money, where we could look ourselves in the eye and say that this is a good investment in terms of sponsoring or marketing [...]. Because we have no interests. (Co1) 
Overall, dealing with publics beyond the own market appears to be a negligible activity. At best, it might provide work for a very few specialised PR agencies. Two of the three consultants we interviewed developed local media and community relations as their distinct business models. Most respondents from business, however, defended a "marketing imperialism" (Lauzen, 1991: 245) as it has been criticised by PR scholars. They did not only downplay the relevance of the region; they also downplayed the relevance of the public sphere in general. The term low-flying takes on an additional meaning here: the remote regional context allows companies to fly low under the radar of public scrutiny.

\section{The need for employer branding}

Dealing with publics beyond the immediate market is not a major concern for companies located in the region of North Jutland. However, there is one noteworthy exception: employer branding is described as a serious challenge. Co1 perceived the location as a disadvantage when attracting talent for entry-level positions:

It's terrible, $[\ldots]$ it's perhaps the biggest issue we have as a company, that we are located here in Aalborg. Because we cannot attract the people that we would want to, in terms of experienced people. But also, the biggest talents, because they would much rather work in Frankfurt or in Amsterdam or London.

Similar concerns were expressed by $\mathrm{Co} 2$ and Co5, who highlighted difficulties in filling specialist positions. Furthermore, all three consultants preferred to work on their own: "I have tried to grow my agency and some years ago I had six employees, but I've never really found anyone who could do the job. So right now, I'm alone. [...] It's very hard to find skilled PR people in this region" (Ag2). What they expect from graduates is rather specific, such as PR writing skills, which might not be sufficiently covered by a broad academic programme:

I've used a lot of interns and trainees and stuff like that throughout the years, but I have stopped doing it, simply because it's a waste of time. And I know [...], I have a responsibility to educate the young and hopeful people coming out of university, but it's a real challenge, because I give them, you know, tasks that are relevant and billable and professional. But it's a struggle for them to do it, because they simply don't know how it works and how a text for a journalist should be, how a case story should be drafted and how a press release is done. They don't have the skills, and I don't have the time to be their educational master, unfortunately. (Ag2)

Most respondents from the companies described a strong dependency on the region as the catchment area for their recruitment activities. They must primarily employ candidates who are already located in North Jutland. Applications from Copenhagen, for example, would be a very rare exception: "So you have to learn [...] to live with the ones you get and then form them precisely into what you need from them" (Co3).

The recruiting process looks different from a student perspective. Al4 said that many of her fellow students from Aalborg University applied for positions nationwide. The ones available on the regional job market would stay for private reasons (Ag1; Al1; Al3; Ba2; Ba4; Co7; Ma3). Families, partners, and friends are in North Jutland and thus, they 
are bound to North Jutland. That, of course, carries the positive side effect that retention is much less an issue than recruitment. Co5, for example, recognised much more self-confidence among graduates in Copenhagen who would increasingly quit a new job only after a few months when they reached the conclusion: "That's not me" (Co5). As discussed before, questions such as, what are "my" strengths, and which job fits best "my" personality, are reflected to a lesser degree by students who decide to enrol in a regional communication programme whose broadness and openness allows them to delegate the crucial questions of "Who am I and what do I want to do with my life?" to an undetermined future.

What can be observed is a student role that triangulates on three levels: it is primarily described by employers (Ag2; Co1; Co2; Co5; CVo3), but alumni (A14) and students (Ma2) also refer to it. We do not argue that it is the only role understanding, but we do argue it is a more salient one on the regional level and matches well with a low-flying communication culture. It reflects a type of "immobile" graduate who studies a communication programme at the hometown university, and all they know is that they want to stay in the region afterward. More flexible and goal-oriented students might go to Copenhagen or abroad in order to find the perfect career match. Against this background, the above-noted employer concerns about a limited recruitment base make sense. As a consequence, some of the respondents discussed the need for a more active employer branding. However, this in turn would undermine the companies' public low-flying strategy:

We have been on local television and $[\ldots]$ we gladly accept that, but it's not a focus. [...] Again, most of our customers won't see those things, but it does help with what I guess you would call employer branding. We get visibility because $[\ldots]$ we do need to hire people, so it helps on that. (A13)

We are not necessarily interested in being seen, but in some cases we are. Because if you want to attract new staff, they need to know you're there. [...] So we need to think of how are we staying attractive for any kind of applicants for different jobs. (Co6; see also Ba1; Ma2)

Thus, at the end of the day, employee recruitment problems might force regional companies to accept a higher degree of public visibility and leave their low-flying comfort zone behind.

\section{Discussion and Conclusion}

In this study, we did not analyse the professional communication of companies whose headquarters are located in global hubs such as New York, London, or Singapore. Instead, we looked at the region of North Jutland in Denmark. How do heads of communication from the biggest companies in the region, PR consultants, alumni, and students perceive communication practices and education? What are their ambitions and expectations? Do they identify with a normatively ambitious boundary-spanning role or does the regional context feed into different understandings? The results reveal such a different understanding. The interviewees discussed some significant characteristics of the regional context that contribute to a distinct constitution of practitioner and student 
roles. First, personal contacts and networking matter more than professional skills. Second, the culture of Janteloven is suspicious towards any kind of self-promotional communication creating the impression that oneself is superior and standing out from the rest. Instead, mediocrity turns into a cultural value. Third, these tendencies are supported by the industry context. Most respondents engage in a more relaxed style of B2B communication. All of this feeds into the role of the low-flying communicator (research question 1). It is the role of an "all-rounder" who prioritises the instrumental logic of marketing over the societal orientation of strategic communication. Thus, the findings of this study reveal the regional practice of low-flying communication as a concept that is challenging the added value of professional communication as societal boundary spanning. Key to the identified concept is the instrumental downplaying of public visibility as a condition for transboundary communication. Instead, the regional public sphere turns into a communicative comfort zone. Critical media and other stakeholders claiming a role of the company as a corporate citizen are largely absent in the data.

The low-flying communicator corresponds with a specific regional student role we identified (research question 2). We might refer to this person as the immobile decisiondelegator. They study at the local university, because North Jutland is their home. For the same reason, students are looking for jobs in the region after graduation. They choose a broad programme because it allows them to postpone reflections about their own professional future. They feel less prepared to take on professional responsibilities. These students need extensive guidance, both in their studies and in their jobs. Such a student role is noteworthy not because it is necessarily the dominating one, but because it makes sense primarily within a regional setting. Accordingly, the data also reveal ambivalences that leave room for a transition into more ambitious role understandings. A rather broad communication programme and equally broad job profiles are attractive for students who deliberately choose the freedom and personal development opportunities such an education and respective career opportunities offer.

In conclusion, two potential matches and two mismatches emerge when relating regional student and practitioner perceptions to each other: 1) the graduate as an immobile decision-delegator being smoothly socialised into the low-flying communicator role constitutes a match of restraint; 2) the ambitious and independent graduate contributing to a polyphonic understanding of corporate communication as societal boundary spanning would be an alternative positive match challenging it. In turn, tensions will arise from "crossbred" role expectations; 3 ) there will be a mismatch if the rather immature decision-delegator is unable to cope with the expected independence at the workplace; and 4) there will also be a mismatch if the ambitious student with a broad horizon is frustrated by a narrow-minded "marketing imperialism" in regional companies. As a practical and normative implication, we conclude that universities and employers should be committed to and support the positive match which would ultimately require a substantial reassessment of the low-flying corporate communication culture.

A single explorative and qualitative case study in unknown territories carries limitations along with it. Future qualitative and quantitative research could take our results as a starting point and look at different organisational contexts, other countries, and other cultures. Qualitative research could scrutinise in more detail the ambivalences of roles and matches we have identified, while quantitative research could measure their context-dependent prevalence. In particular, comparative research designs could over- 
come limitations of this study by systematically contrasting metropolitan PR practices with regional PR practices. Moreover, regional PR in the private sector, which has been the focus of this study by including only companies and agencies, could be compared with PR roles in public institutions and civil society institutions. Going forward, both qualitative research, identifying modified or different types of regional communication roles, and quantitative research, testing the generalisability of our case study findings, would be valuable.

Moreover, our results could inspire theory building in PR. Here, we have provided the first study extracting a PR role from a regional context and relating it to aspirations and expectations of communication students. We have identified roles not previously identified by any study. There is a reason for it: what we found is the paradoxical role of a PR practitioner who is not self-promotional. Such a role has been overlooked by previous research because it started from the unquestioned assumption that PR is necessary always and everywhere. A potentially delegitimising PR role questioning the functionality of publicity in distinct social contexts turned into a blind spot within existing PR role research. Future theory-building could help to incorporate the paradox of the low-flying communicator into existing role models.

As a practical implication, we acknowledge the regional effectiveness of low-flying communication at least in the short term. However, the refusal of a boundary-spanning role that would significantly engage with publics beyond the market could, in the long term, decrease the organisation's ability to learn, innovate, and build relationships with those publics. The dilemma becomes most visible in the field of employer branding. Graduates who search for their future employer by consulting the Yellow Pages of the local phonebook might provide less sustainable value and inspiration than the ones keen to expose themselves to a whole world of opportunities.

Finally, what might be effective from an organisational perspective is not necessarily desirable on normative grounds: Should companies located in remote regions not also be accountable to their publics and accept public scrutiny? Should it not be an ethical commitment to engage with publics, even though there might be no immediate return of investment? Discussing these questions is important, while "blame games" should be avoided. There is no reason for a company to impose a proactive public relations model upon regional media if these can be satisfied with promotional marketing material. In turn, there is no reason for media to do more than transmitting such marketing material, if the audience expects nothing more than product information from regional business news. Hence, "flying low" under the radar of public scrutiny makes sense and is effective for many communication practitioners in regional settings. Nonetheless, a normative dilemma remains: the low-flyer veers away from the ideal of boundary spanning as a professional role understanding in PR.

\section{References}

Aldrich, H., \& Herker, D. (1977). Boundary spanning roles and organization structure. The Academy of Management Review, 2(2), 217-230. http://dx.doi.org/10.5465/amr.1977.4409044

Berkowitz, D., \& Hristodoulakis, I. (1999). Practitioner roles, public relations education, and professional socialization: An exploratory study. Journal of Public Relations Research, 11(1), 91-103. http://dx.doi. org/10.1207/s1532754xjprr1101_04

Bromgard, G., Trafimow. D., \& Linn, C. (2014). Janteloven and the expression of pride in Norway and the United States. The Journal of Social Psychology, 154(5), 375-378. http://dx.doi.org/10.1080/002245 45.2014.914884 
Cameron, G. T., Cropp, F., \& Reber, B. H. (2001). Getting past platitudes: Factors limiting accommodation in public relations. Journal of Communication Management, 5(3), 242-261. http://dx.doi. org/10.1108/13632540110806802

Cooley, C. H. (2007). Human nature and the social order (rev. ed.) New York: Charles Scribner's Sons. Retrieved April 24, 2020, from https://brocku.ca/MeadProject/Cooley/Cooley_1902/Cooley_1902f.html (Original work published 1922).

Dozier, D. M., \& Broom, G. M. (1995). Evolution of the manager role in public relations practice. Journal of Public Relations Research, 7(1), 3-26. http://dx.doi.org/10.1207/s1532754xjprr0701_02

Falkheimer, J., \& Heide, M. (2014). From public relations to strategic communication in Sweden: The emergence of a transboundary field of knowledge. Nordicom Review, 35(2), 132-138. http://dx.doi. org/10.2478/nor-2014-0019

Glaser, B. G., \& Strauss, A. L. (1967). The discovery of grounded theory: Strategies for qualitative research. Chicago: Aldine. http://dx.doi.org/10.4324/9780203793206

Hoffmann, J. (2016). All roads lead down under? Ethnocentrism among Australian corporate communication practitioners. Communication Research and Practice, 2(2), 244-262. https://doi.org/10.1080/2204145 1.2016.1186486

Hoffmann, J., Röttger, U., \& Jarren, O. (2007). Structural segregation and openness: Balanced professionalism for public relations. Studies in Communication Sciences, 7(1), 125-146. https://boris.unibe.ch/ id/eprint/29427

Hutton, J. G. (2010). Defining the relationship between public relations and marketing: Public relations' most important challenge. In R. L. Heath (Ed.), The Sage handbook of public relations (pp. 509-521). London: Sage. http://dx.doi.org/10.4135/9781452220727.n14

Johansson, B., \& Larsson, L. (2015). The complexity of public relations work: PR managers in the public and private sector in Sweden. Nordicom Review, 36(1), 125-139. https://doi.org/10.1515/nor-2015-0010

Kristensen, N. N. (2010). Nice to have - or need to have? The professional challenges of the communication sector. Nordicom Review, 31(2), 135-150. https://doi.org/10.1515/nor-2017-0134

Lauzen, M. M. (1991). Imperialism and encroachment in public relations. Public Relations Review, 17(3), 245-255. http://dx.doi.org/10.1016/0363-8111(91)90021-C

Lauzen, M. M. (1992). Public relations roles, intraorganizational power, and encroachment. Journal of Public Relations Research, 4(2) 61-80. http://dx.doi.org/10.1207/s1532754xjprr0402_01

Ledingham, J. A., \& Bruning, S. D. (1998). Relationship management in public relations: Dimensions of organization-public relationship. Public Relations Review, 24(1), 55-65. http://dx.doi.org/10.1016/ S0363-8111(98)80020-9

Lee, J. (2013). Encroachment in public relations. In R. L. Heath (Ed.), Encyclopedia of public relations (2nd ed., vol. 1) (pp. 290-292). London: Sage. http://dx.doi.org/10.4135/9781452276236.n160

Leichty, G., \& Springston, J. (1996). Elaborating public relations roles. Journalism and Mass Communication Quarterly, 73(2), 467-477. http://dx.doi.org/10.1177/107769909607300215

Meznar, M. B. (2005). The organization and structuring of public affairs. In P. Harris, \& C. Fleisher (Eds.), The handbook of public affairs (pp. 187-196). London: Sage. http://dx.doi.org/10.4135/9781848608108.n12

Miles, R. H. (1987). Managing the corporate social environment: A grounded theory. Englewood Cliffs, New Jersey: Prentice Hall.

Morsing, M., Schultz, M., \& Nielsen, K. U. (2008). The 'Catch 22' of communicating CSR: Findings from a Danish study. Journal of Marketing Communications, 14(2), 97-111. http://dx.doi. org/10.1080/13527260701856608

Myers, K. K., Jahn, J. L. S., Gailliard, B. M., \& Stoltzfus, K. (2011). Vocational anticipatory socialization (VAS): A communicative model of adolescents' interests in STEM. Management Communication Quarterly, 25(1), 87-120. https:www.doi.org/10.1177/0893318910377068

Röttger, U., Hoffmann, J., \& Jarren, O. (2003). Public relations in der Schweiz: Eine empirische studie zum berufsfeld öffentlichkeitsarbeit [Public relations in Switzerland: An empirical study on the field of public relations]. Konstanz, Germany: UVK.

Springston J. K., \& Leichty, G. (1994). Boundary spanning activities in public relations. Journalism Quarterly, 71(3), 697-708. http://dx.doi.org/10.1177/107769909407100320

Sriramesh, K., \& Verčič, D. (Eds.) (2020). The global public relations handbook: Theory, research and practice (3rd ed.). New York: Routledge.

Trittin, H., \& Schoeneborn, D. (2017). Diversity as polyphony: Reconceptualizing diversity management from a communication-centered perspective. Journal of Business Ethics, 144(2), 305-322. http://dx.doi. org/10.1007/s10551-015-2825-8

Copyright: (C) 2020 The Author(s) and Nordicom. This is an Open Access article distributed under the terms of the Creative Commons Attribution 4.0 International License (CC BY-NC-ND 4.0). 